\title{
Procesos educativos vivenciados por cicloactivistas en la promoción del ciclismo urbano
}

\author{
Educational processes experienced urban cyclists in the promotion bicycling
}

Processos educativos vivenciados por cicloativistas na promoção do ciclismo urbano

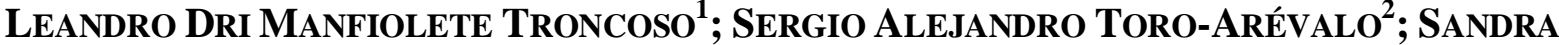 \\ SOLEDAD TronCOSO ROBLES DRI MANFIOLETE ${ }^{3}$ \\ Universidad Austral de Chile, UACh, Valdivia, Chile
}

\begin{abstract}
RESUMEN
El objetivo de esta investigación fue comprender los procesos educativos vivenciados por cicloactivistas en la promoción del ciclismo urbano. Para la metodología, se utilizó el abordaje fenomenológico 4 Ecological Cognition comprendidos como procesos cognitivos encarnados, situados, extendidos y enactivos con el ambiente social-natural. Fueron realizadas entrevistas semiestructuradas con siete personas de Brasil, Colombia y Uruguay teniendo como criterios de inclusión, ser cicloactivista militante y desarrollar proyectos temáticos con cicloturismo, espacios de convivencia y género donde emergieran las unidades de significado: a) cicloturismo como praxis de liberación; b) Promoción del bicicultura; c) ser mujer ciclista urbana resultando en la categoría "La práctica cicloactivista".
\end{abstract}

Palabras clave: Ciclismo Urbano. Procesos Educativos. Movilidad Activa. Derechos Humanos.

\begin{abstract}
The objective this research to understand educational processes experienced by cycloativists in the promotion of urban bicycling. For the methodology, we used phenomenological approach 4 Ecological Cognition understood as cognitive processes embodied, situated, extended and enactive with the social-natural environment. Semistructured interviews were conducted with seven people from Brazil, Colombia and Uruguay, having criteria for inclusion, being a militant cycloativist and developing thematic projects with cycle tourism, spaces of coexistence and gender where the units of meaning emerged: a) cycle tourism as liberation praxis; b) Promotion bicycling; c) urban bicyclist woman resulting in the category "Cycloactivist practice".
\end{abstract}

Keywords: Bicycling. Educational Process. Active Mobility. Human Rights.

\section{RESUMO}

O objetivo desta pesquisa foi compreender os processos educativos vivenciados por cicloativistas na promoção do ciclismo urbano. Para a metodologia, foi empregada a abordagem fenomenológica 4 Ecological Cognition entendida como processos cognitivos encarnados, situados, estendidos e enativos com o ambiente social e natural. Foram realizadas entrevistas semiestruturadas com sete pessoas do Brasil, Colômbia e Uruguai, tendo como critérios de inclusão, ser cicloativista militante e desenvolver projetos temáticos com cicloturismo, espaços de convivência e gênero surgindo as unidades de significado: a) cicloturismo como práxis de libertação; b) Promoção da bicicultura; c) ser mulher ciclista urbana, resultando na categoria "Prática Cicloativista".

Palavras-chave: Ciclismo Urbano. Processos Educativos. Mobilidade Ativa. Direitos Humanos.

\footnotetext{
${ }^{1}$ Doctorando en Ciencias Humanas. Mención Discurso y Cultura - UACh. E-mail: leandro_dri@hotmail.com

${ }^{2}$ Profesor de la Facultad de Filosofía y Humanidades - UACh. E-mail: seatoro@ gmail.com

3 Magíster en Educación. Mención Política y Gestión Educativa - UACh. E-mail:
sandra.troncoso.robles@gmail.com
} 


\section{INTRODUCCIÓN}

La promoción de hábitos de vida saludable a través del ciclismo urbano es una alternativa responsable (JONAS, 2006) al generar eficiencia energética con equidad (RIECHMANN, 2012; ILLICH, 2015) y movilidad activa no-violenta (NATARAJ, 2013). Tiene efectos para la mejora de la salud ambiental (SALDIVA, 2018), para la planificación urbana que privilegien el uso de la bicicleta para todas las edades (PUCHER; BUEHLER, 2012; COLVILLE-ANDERSEN, 2018) y a nivel cognitivo tanto orgánico como en la dimensión subjetiva y social con la realización de la actividad periódica del pedalear contribuyendo para la promoción de la salud y prevención de enfermedades crónico-degenerativas (SARMIENTO et al., 2017) y como alternativa de comprensión cultural recurrente que conlleve experiencias y conocimientos enmarcados en ritmos, velocidades, desplazamientos y vinculación con una herramienta-artefacto extendida a una posibilidades humana de actuación (DURT; FUCHS; TEWES, 2017).

De igual forma, en lo referente a las cartas de compromiso de la Organización de las Naciones Unidas (ONU), destacamos los Objetivos del Desarrollo Sustentable (ONU, 2015A) con la bicicleta involucrada en las 17 metas (ECF, 2016), el Acuerdo de Paris (COP-21) (ONU, 2015b), el informe del Secretario General sobre Transporte Sustentable (ONU, 2016a) y la Nueva Agenda Urbana (Hábitat-III) con el Reporte Mundial de las Ciudades (WCR) (ONU, 2016b), reivindicaciones que indican por una actualización a la escala humana del planeamiento estratégico de la política pública (GEHL, 2013). La discusión situada a la República Federativa del Brasil, la actuación de los cicloactivistas amparados en el Código de Transito Brasileño (CTB) (BRASIL, 1997), el Estatuto de las Ciudades (BRASIL, 2001), el Programa Bicicleta Brasil (PBB) (BRASIL, 2007; 2018), la Política Nacional de Movilidad Urbana (PNMU) (BRASIL, 2012a), la Política Nacional de Promoción de la Salud (PNPS) (BRASIL, 2006) y el Cuaderno de Elaboración del Plan de Movilidad Urbana (BRASIL, 2015).

Este artículo tuvo por objetivo comprender los procesos educativos vivenciados por cicloactivistas en la promoción del ciclismo urbano como parte de una reivindicación legítima del derecho humano a la movilidad activa sustentable por bicicleta. Nuestra referencia discursiva está situada en la participación ciudadana de la militancia cicloactivista entendida como procesos cognitivos encarnados, situados, extendidos y enactivos de construcción cultural para transformación del ambiente social (TORO-ARÉVALO; MAUTZ, 2014; SERGIO et al., 2014).

\section{Metodología}

Para esa investigación, se emprendió la metodología fenomenológica 4Ecological Cognition de los procesos cognitivos encarnados, situados, extendidos y enactivos (NEWEN; DE BRUÍN; GALLAGHER, 2018). Para los autores, dada las bases de la ciencia tradicional centrarse en la explicación de los procesos cerebrales y representacionales del conocer humano, esa abordaje busca la comprensión cognitiva como estado tanto por dependencia causal (cerebro-cuerpo) y por medio extra-corporal (cerebro-cuerpo-ambiente) es decir, los procesos cognitivos son constituyentes basados en reglas sistémicas desplegadas en el ejercicio mismo del mundo-vida (Lebenswelt) en la resolución de problemas inmediatos que se presentan (TORO-ARÉVALO, 2017). Así, nuestra referencia de sentido fenomenológica comprende las acciones llevadas a cabo por la percepción del sujeto como ser encarnado y situado en su afectividad (SERRES, 2011). Para Kiverstein (2018) los procesos cognitivos son sistemas de 
percepción-acción teniendo como base el ajuste adaptativo de la persona con su entorno cuyas propiedades dinámicas de esa interacción recíproca, fundamentan el éxito de la cognición extendida, es decir, la influencia causal se interpone en el modo de modelar el agente y el ambiente que funcionan independientemente.

En relación a los procedimientos de investigación, al comprendemos procesos cognitivos correspondientes a los procesos educativos, afirmamos que siempre hay un ambiente de relación con el otro ser humano. Para Gonçalves Junior et al. (2016) los procesos educativos vivenciados ocurren en una relación mutua de aprendizaje teniendo como presupuesto una relación dialógica con intencionalidad dirigida hacia la cooperación, la superación, el ser más, demandando autonomía, posibilidad de decisión y de transformación. Para Oliveira et al. (2014) tales condiciones permiten a los involucrados comprender valores y códigos del grupo, de la comunidad y de la sociedad en que viven generando la posibilidad de reflexionar sobre su propia condición de pertenencia al mundo donde cada actor indagado, manifestó a partir de su propia praxis en el contexto investigado, un modo particular de existencia situada.

La investigación fue desarrollada a partir de dos experiencias realizadas durante la maestría defendida en el Programa de Postgrado Ciências da Motricidade, Universidade Estadual Paulista "Júlio de Mesquita Filho" (UNESP), área de actuación Pedagogía de la Motricidad Humana, línea "La Naturaleza Social del Cuerpo":

a) en el según semestre de 2015, la realización de intercambio académico en la Universidad de Antioquia (UdeA) participando del " $5^{\circ}$ Coloquio Internacional de la Educación Corporal: modos de experiencia desde los cuerpos" y en la Universidad de Cundinamarca (UDEC) participando del "I Seminario Construyendo Territorio desde la Bicicleta" pedaleando 1500 kilómetros entre Medellín y Bogotá al encuentro de personas involucradas con la cultura de bicicleta en la realización de doce entrevistas;

b) en el primer semestre de 2016, un viaje en bicicleta para entrevistar 30 cicloactivistas denominada "Pedaling for Cityzenship" (MANFIOLETE; BERSI, 2016) pedaleando aproximadamente 4500 kilómetros entre Brasil, Uruguay, Argentina e Chile por las ciudades de Maringá, Curitiba, Joinville, Blumenau, Balneário Camboriú, Florianópolis, Porto Alegre, Pelotas, Montevideo, Buenos Aires, La Plata, Mendoza y Santiago para participar del "V Foro Mundial de la Bici: Energía Humana, Poder Ciudadano".

A partir de los criterios de inclusión: a) ser cicloactivista militante; b) promoción del bicicultura y c) desarrollo de proyectos dirigidos a las temáticas cicloturismo, espacios culturales y género, realizamos entrevistas semiestructuradas yendo al encuentro de cada sujeto situado en sus ambientes sociales dejando libres con preguntas relacionadas a su modo de vida con la finalidad de exponer el sentido de su práctica cicloactivista en determinados contextos (DENZIN; LINCOLN, 2012). Así, buscamos comprender las intencionalidades vinculantes a sus acciones, los significados emitidos en los discursos por cada actividad desarrollada, el sentido del proceso histórico de participación ciudadana con las dificultades enfrentadas en el cotidiano con bicicleta y las motivaciones involucradas partiendo de la pregunta: ¿Qué es ser cicloactivista?

A partir de su relevancia, su localidad en el territorio sudamericano y diversidad del proyecto temático, seleccionamos las siguientes personas:

1. Carlos E. Carvajal, director del "Pedaleando Alma" para la promoción del cicloturismo en Medellín, Colombia ${ }^{4}$.

\footnotetext{
${ }^{4}$ Más informaciones: https://pedaleandoalma.com/
} 
2. Leandro Karam, idealizador del "Via Ecológica" para la promoción del cicloturismo agroecológico en Pelotas (RS), Brasil (CARDOSO; KARAM; SANTOS, 2016).

3. Fernando Rosembaum, gestor del espacio de convivencia "Bicicletaria Cultural" en Curitiba (PR), Brasil ${ }^{5}$.

4. Sérgio Barba, gestor del "Libera tu Bici" para recuperación de bicicletas en Montevideo, Uruguay ${ }^{6}$.

5. Luis Claudio Brito Patricio, Máster en Gestión Urbana (PUC-PR), idealizador del proyecto "De Bike ao Trabalho" en Curitiba (PR), Brasil (PATRICIO, 2016).

6. Marina Kohler Harkot, Máster en Arquitectura y Urbanismo (USP), coordinadora del Grupo de Trabajo Género, Asociación de los Ciclistas Urbanos de São Paulo ( "CICLOCIDADE”) en São Paulo (SP), Brasil (HARKOT, 2018).

7. Caroline Lemos, Artista Visual integrante del colectivo de mujeres cicloactivistas "Saia de Bici" en la ciudad de Curitiba (PR), Brasil.

Los participantes firmaran el Término de Consentimiento Libre y, Esclarecido (TCLE) acordando con los procedimientos de la investigación y con la publicación con sus nombres reales y ocupaciones laborales, también siendo traducidos los discursos transcritos del portugués para el español. El proceso fue registrado en la Plataforma Brasil, comprobante 029413/2015, parecer 1.202.636, sometido al Comité de Ética e Investigación, Instituto de Biociências de Rio Claro, Universidade Estadual Paulista “Júlio de Mesquita Filho", data 27/03/2015, registro CAAE: 43889115.1.0000.5465, de acuerdo con la Resolución 466, Consejo Nacional de Salud (CNS) (BRASIL, 2012b) con el trabajo contando con apoyo institucional para beca de magíster, proceso 14781412, Coordenadoria de Aperfeiçoamento de Pesquisa em Ensino Superior (CAPES).

Para análisis de los datos, resaltamos la individualidad expuesta por la actitud, disposición y suspensión de sus creencias con la transcripción de cada discurso identificada a través de síntesis analíticas agrupadas por comparación y por variación imaginativa de los investigadores donde acabó emergiendo la comprensión general discursiva (BICUDO, 2011). Durante la reducción fenomenológica, la configuración discursiva contextualizada a los sujetos investigados generando las unidades de significado: a) Cicloturismo como praxis de liberación; b) Promoción del bicicultura; c) Ser mujer ciclista urbana que, en nuestra comprensión situada, componen el fenómeno social del cicloactivismo convergentes para la categoría "La práctica cicloactivista".

\section{RESUlTADOS}

\section{A) CiCloturismo COMO PRAXIS DE LIBERACIÓN}

En esa unidad de significado, el cicloturismo tornase una progresión pedagógica del ciclismo urbano vislumbrando la oportunidad para el sujeto que viaja en bicicleta conocer nuevos territorios, hizo con que Carlos Carvajal, director del "Pedaleando Alma", empezó pedaleando en la ciudad solamente en la edad adulta, tiene buscado en los más de 12 años viajando en bicicleta, descubrir nuevos conocimientos destacando una experiencia significativa vivenciada durante 529 días pedaleando por Sudamérica:

Recorrí nueve países, 25.000 kilómetros en veinte meses, tenía un itinerario buscando conocer lugares nuevos, encontraba la manera de seguir avanzando,

\footnotetext{
${ }^{5}$ Más informaciones: https://bicicultural.com/

${ }^{6}$ Más informaciones: http://www.liberatubicicleta.org/
} 
planeaba el trayecto a cada 15 días dividida en etapas, acampaba, era recibido en alguna casa y tiene los aspectos personales de introspección, libertad, salir de la cotidianidad y vivir intensamente, conocer las culturas eres algo intrínseco al observar historias y corroborar como son la gente de otros lugares, establecer contactos para volver regresar, renovar mi mente y con eso en medio del camino, aprehendí sobre la soledad, el esfuerzo, la disciplina y la importancia del viajar en la vida para romper barreras, eliminar mitos, acercar a los corazones y entender que todo está compartido.

Durante esa trayectoria, Carlos Carvajal recuerda de su pasaje por Córdoba, Argentina que, después de contacto con cicloactivistas, fue recibido por estudiantes con bicicleta colaborando para modificar la política de infraestructura cicloviaria:

Durante mi recorrido recibí un mensaje de una fundación francesa llamada Planet donde tuvo una gente en la ciudad de Córdoba, Argentina que se involucró en ese proceso con los profesores del colegio Dante Alighieri que iban diciendo a sus alumnos que Carlos Carvajal, el mensajero ecológico ya estás cerca, falta 3 meses, falta 1 mes... cuando llegué había 1000 niños en la calle con bicicleta, paramos las calles hasta al colegio, fue el momento más espectacular del viaje, estuvo embajador de Italia y autoridades de la ciudad, fue transformador porque nunca tuvieran oportunidad igual, escribimos carta para las autoridades reclamando infraestructura cicloviaria, meses después el Banco Mundial regaló 10 millones de dólares para movilidad por bicicleta, fue un sentimiento de alegría, lloré como un niño de emoción, agradecimiento, de amor por la vida.

Después del regreso de esa viaje, decide aplicar sus conocimientos ayudando en la organización del "IV Foro Mundial de la Bici: Ciudades para Todos" realizado en 2015 en la ciudad de Medellín, contexto en que fue otorgado reconocimiento por la idea "Zonas de Tráfico Calmado o Zonas 30" a través de la plataforma ciudadana Mi Medellín. También destaca su participación en la "Mesa Metropolitana de la Movilidad no Motorizada", ayudando a generar el "Plan Maestro Metropolitano de la Bicicleta del Valle de Aburrá” (ÁREA METROPOLITANA, 2015):

Cuando regresé del viaje, vengo con un plan estratégico de impulsar el ciclismo urbano en Medellín haciendo contacto con políticos, empresarios y activistas demostrando haber un problema de movilidad, pues los ciclistas no tienen prioridad en las vías y ahora estoy dedicando a viajar en bicicleta por toda Colombia incentivando a la gente a hacer lo mismo. Trabajé tres años de manera voluntaria buscando sensibilizar las personas participando en mesas de trabajo con entidades públicas, a ejemplo, la Mesa Metropolitana de movilidad no-motorizada con municipios de la Región Metropolitana Valle de Aburrá, organizamos el 4 Foro Mundial de la Bicicleta, ayudamos a legitimar el sistema de bicicletas públicas ENCICLA, antes había 100 bicicletas y dos estaciones, ahora son 1500 bicicletas y 50 estaciones, generamos conocimiento para que la gente que trabaja en las instituciones conozca donde hay estaciones y como utilizar el sistema, también producimos material para la prensa demostrando la problemática con la cultura ciudadana al redor del uso de la bicicleta haciendo activismo, pintando calles, pusimos bicicletas blancas en lugares de ciclistas muertos.

En otra experiencia de esa unidad de significado, Leandro Karam, idealizador de la "Vía Ecológica" para desarrollo del cicloturismo agroecológico en la Serra do Tapes, busca hacer visitas guiadas con bicicleta en propiedades de la agricultura familiar:

Trabajamos con los municipios de Pelotas, Camaquã, Cambuçu, Morro Redondo, Arroio de Padre y São Lourenço do Sul, reunidos en forma de 
circuito con sello por la Sierra de los Tapes, territorio contemplado con la mayor concentración de agricultura familiar en Brasil. A través de itinerarios agroecológicos, estamos empezando a cosechar frutos del trabajo desde el primer evento con el cicloturismo en una propiedad rural en noviembre de 2013. A partir del año 2014, pasamos a organizar una agenda anual con las visitas involucrando la experiencia de aliar el productor rural en una dinámica de eventos en torno al circuito, así como lo hacemos en la ciudad cuando tiene pedalada nocturna todo el jueves para divulgación con actividades todos los domingos, lleva para almorzar y volver, tiene personas que van en autobús hasta el lugar, pedaleas pequeñas distancias con estructura de coche de apoyo y enfermero para el principiante pedalear con seguridad y al mismo tiempo montando el servicio y sensibilizando a los agricultores con más de 100 propiedades de la región en proceso de presentación formal del proyecto. Al principio comenzamos a trabajar con los agricultores de la feria, algunos toparon la propuesta, otros rechazaron, pero ahora participan en sus propiedades, estamos avanzando debido a la empatía desarrollada.

Leandro Karam caracteriza el cicloturismo agroecológico como una alternativa viable al turismo de masa por agregar valor a la persona que viaja en bicicleta:

Estamos hablando de dos conceptos de turismo: turismo de masa en ir a conocer un lugar y turismo de experiencia en formar parte del lugar, una persona que se satisface ir en la Torre Eiffel tomar una foto y ni siquiera sabe qué es de ese lugar sólo para mostrar que fue en ese lugar, en nuestro caso es lo contrario, quien practica ese tipo de turismo hoy, son personas con capacidad de conocimiento para buscar ese tipo de experiencia con sencillez y acogida saliendo del estrés de la ciudad buscando experiencias simples en el campo, sin embargo, son que es una de las más grandes de la historia de la humanidad, y que, por lo tanto, es una de las razones por las que la mayoría de las veces, el efecto salto cuántico que implica una ecología de relaciones.

\section{B) Promoción del bicicultura}

En esa unidad de significado, Fernando Rosembaum, uno de los mentores del espacio de convivencia "Bicicletaria Cultural", también sede de la Asociación de los Ciclistas Urbanos del Alto Iguazú ( "CICLOIGUAÇU”), nos relata hechos históricos del movimiento cicloactivista curitibano:

En 2002 empecé a unirme con un grupo de amigos en Curitiba, universitarios de diversas áreas que estaban practicando la ciudad con acciones que elogiaban la bicicleta y luego se transformaron en reclamación con el poder público para la requisición de infraestructuras previstas, desde 2003 sólo se enrollaron que se ha convertido en una de las más antiguas del mundo, y que se ha convertido en una de las más antiguas del mundo. En 2010 creamos la Asociación de Ciclistas del Alto Iguazú durante una exposición de arte, Curitiba siempre estuvo ligado a las manifestaciones culturales con las actividades cicloactivistas y, en 2011, junto a Patricia Valverde, abrimos el espacio de convivencia Bicicleta Cultural con sede el honor de la asociación que cuenta con la galería de arte Farol, el mago jardinero, mecánica colaborativa, tienda, cursos, actividades artísticas, un ecosistema que se formó aquí. Creemos que eses lugares forman capital humano convirtiéndose referencia como centro de información, somos pioneros en el emprendimiento que mezcla negocio con actividades de impacto social y que funcionaría en cualquier ciudad.

El modelo de urbanización cambió drásticamente nuestra forma de ser-ahí con el otro, así como el estar en el mundo, lo que indica la urgente necesidad de encarar el 
tránsito como un problema colectivo para aumentar participación ciudadana y alcanzar la humanización del espacio público urbano. Para Fernando Rosembaum, la comparación de la bicicleta como "caballo de los pobres" marca la condición resistente del ciclista urbano que castiga aquellos que no tienen el espíritu de enfrentamiento:

Yo tengo la imagen del caballero amazonas en su tiempo enfrentando vehículos pesados soltando toneladas de humo tóxico a gran velocidad y usted está sin armadura, un caballero desnudo, si esos ciclistas dejan de pedalear, las calles se harán sólo para automóviles, esas personas están luchando, se imponiendo, conviviendo para conseguir en el futuro que sus hijos también pedalean, una resistencia por el compartir la ciudad, nosotros percibimos que todo el mundo y el gobierno no da nada de mano bendecida, es una cuestión política, tiene que conocer los representantes locales y reclamar a sus representantes derechos para encontrar soluciones y estudiar los proyectos que quieren instalar.

En otra experiencia de espacios de convivencia promotores de la bicicultura, destacamos el proyecto "Libera tú Bici" que, para Sergio Barba, ese espacio de convivencia visa recuperar bicicletas con la generación de procesos educativos al estilo 'hágalo usted mismo' arreglando una bicicleta cuya iniciativa consta de un contenedor donde están guardadas las herramientas y también bicicletas recuperadas con las personas se reuniendo todos los sábados para auxiliar aquellos que desean obtener aprendizaje técnico sobre mecánica, además de conocer nuevas amistades ciclistas:

\footnotetext{
Hacen unos años empecé a hacer parte de la masa crítica, éramos entre 40 a 50 personas y eso comenzó a crecer, también nucleamos para jugar bici polo, entonces apareció Paulo Alvarenga con la idea innovadora de Libera Tu Bicicleta. Fuimos nos juntando por afinidades para generar e funcionar y desde que arrancamos entregamos aproximadamente 250 bicicletas siendo caracterizado como un taller comunitario donde recibimos bicicletas donadas que estaban abandonadas, nosotros recuperamos y ponemos a funcionar para aquellos que necesiten donde ha crecido por la cantidad de gente frecuentando, en principio estábamos en la casa de Pablo trabajando en la sotera de su casa y a partir de eso, comenzó a juntar cada vez más gente, era incómodo, empezó a complicar la gestión dentro de ese espacio y tuvimos la suerte desde el Velódromo de Montevideo que nos contactaran para ofrecer un espacio en cambio de servicios, ellos iban a implementar un sistema de préstamo gratuito donde tenían comprado las bicicletas y nosotros hacíamos el mantenimiento y prestarlas no momento que estuviésemos ahí a la gente que pasaba para andar en bicicleta en el Parque Batlle y con la retribución de tener un espacio para el taller nuestro, es un contenedor, las bicicletas reparadas quedan están adentro y las que están para reparar afuera, todos los fines de semana que arrancamos siempre llena de gente.
}

Debido al carácter comunitario de esta iniciativa germinada en el movimiento masa crítica de Montevideo en diversas alianzas con instituciones públicas, a ejemplo, Universidad de la República (UdelaR) con el "Programa Unibici" y la Intendencia de Montevideo, el mejor camino para la convivencia viaria no son vías segregadas, sino la disminución de la velocidad vial:

Nosotros hemos logrado meter dentro de un circulo de colectivos cicloactivistas, tanto de la universidad como de un grupo viejo llamado Urubike y también estamos metido en las instituciones con el tema movilidad sea dentro del municipio de Montevideo como a nivel nacional de Uruguay, entonces ahora nos pregunta cosas y piden consejos, como ejemplo, incluyere la bicicleta dentro de los manuales de conducción y en las infraestructuras y 
dentro de colectivos, hay varios discursos, nosotros creemos en la importancia de bajar las velocidades en general de la ciudad que va a ser más segura en vez de poner ciclovías segregadas y hacer que la bicicleta quede separada del tránsito, entonces tenemos esa diferencia conceptual porque una es una es inversión de infraestructura que por lo diese nuestro gobierno, no tiene ese dinero y otra más sencilla es bajar la velocidad del tránsito que para hacer solamente con interés político.

Teniendo en cuenta la promoción de bicicultura realizada en diferentes espacios de la vida social, Luis Patricio, que formó parte de la organización del "III Fórum Mundial da Bicicleta: a Cidade em Equilíbrio" realizado en 2014 en la ciudad de Curitiba (PR) (BELOTTO et al., 2014) relata su agenciamiento cultural en ambiente laboral reivindicando mejores condiciones para el trabajador ciclista urbano:

\begin{abstract}
La bicicleta pasó a estar presente cuando vendemos el coche en la vida personal y en la vida profesional donde pasé a desarrollar dentro de la Compañía de Tecnología de la Información y Comunicación de Paraná (CELEPAR) donde trabajo un programa de incentivo a los empleados para andar en bicicleta bautizado de Programa Transporte libre donde realizamos actividades de acompañamiento para quien quiere comenzar a pedalear, exposiciones, paseos y recientemente después de diez años, fue construido un bicicletario con 66 plazas. Quiero entender cómo las medidas de incentivo influencian a las personas a adoptar la bicicleta porque hoy en la empresa tenemos más de 100 empleados que pedalean al trabajo, no conozco otras empresas con esa iniciativa, me gustaría saber si lo que hemos hecho tiene que ver con otro fenómeno para replicar la experiencia en otros lugares.
\end{abstract}

En estos términos, se puede decir que el acto de pedalear en la ciudad es una motricidad periférica o marginal, pero con posibilidad pedagógica emergente (CARMO, 2017) donde la bicicleta antes marginada o vista como juguete propio de la infancia, tiene relevancia en el mundo social dada la posibilidad de observar procesos educativos de respeto al otro y solidaridad en vías urbanas para un tránsito más seguro. Luis Patricio destaca la inconveniencia normativa que el ciclista causa cuando llega al trabajo pedaleando, principalmente por ese ambiente no estar preparado para recibir los ciclistas con la idea negativa del riesgo y sus consecuencias en el cotidiano laboral:

\begin{abstract}
Inconveniente por no ser normal ir pedaleando al trabajo y por eso indago del porque la ciudad no está planeada para ciclistas con pocas ciclovías, al contrario, las calles y los cruces diseñados para los conductores transitar a alta velocidad. A pesar del código de tránsito mencionar que, en cualquier conversión dé la preferencia a la movilidad activa, el conductor a veces tiene la intención de ayudar al ciclista o peatón que está cruzando, sin embargo, corre el riesgo de llevar un golpe por detrás dado que la planificación está estructurada para la fluidez del transporte motorizado, entonces es inconveniente estar en bicicleta por no haber un lugar construido para ese sujeto y eso influye a todos, incluso los establecimientos comerciales, muchos quisieran pedalear, pero no hay lugar para parar o el jefe quiere que sus empleado llegue de traje y corbata y aún no le gusta y no quiere.
\end{abstract}

\title{
C) SER MUjer CICLISTA URBANA
}

En la unidad de significado "condición de género en ser mujer ciclista urbana" Marina Harkot relata la condición libertaria en ser mujer ciclista urbana y de los beneficios y condiciones de pedalear cotidianamente en la ciudad de São Paulo:

Yo vivía en el barrio de Pompeia, así empecé a atravesar puente, pedalear en São Paulo en la calle en cualquier momento del día cambió mi vida con 
relación al espacio y distancia, llego más rápido en la universidad si se compara al transporte público, tengo autonomía de horarios, consigo hacer más cosas y conectarlas en mi agenda, tengo un amigo que salíamos a pedalear la noche donde, fue genial para romper los miedos. La bicicleta se ha vuelto más que un medio de transporte, percibí la voluntad por sí solo, voy a dar una vuelta para limpiar la cabeza y hacer ejercicio y la facultad con trabajo de casa cerebral, el pedaleo ayuda a organizar las ideas. En realidad, lo que te mueves se convierte en la solución de los problemas cuando estás pedaleando y en ese momento, antes de estás dentro del autobús leyendo o en celular, con la bicicleta no se puede hacer nada más, tienes que estar atenta al tránsito siguiendo su camino y cuando pasé a andar en bicicleta fija, percibí un cambio de carácter que, de la utilidad pasa por la frustración que se tiene en medio del camino en la relación con la ciudad y de una forma de mantener en movimiento.

Al contrario de lo que se imagina, para Marina Harkot la bicicleta promueve su seguridad basada en la presencia plena que se debe tener para transitar en la ciudad siendo altamente relevante, el pedalear como estado de presencia y alerta permanente sobre sí mismo (tanto a nivel fisiológico, concentración) como del entorno en el que se fluye. Por otro lado, al presenciar situaciones de prejuicio al oír cosas de cuño sexual, sin embargo, lo primordial es tener una conducta ética para seguir adelante pedaleando:

Me siento segura con la bicicleta comparada al transporte motorizado, puedo pedalear a noche por esa zona oeste y centro expandido. Sucede que no uso casco, un hombre en la calle me grita ¿ahí gata donde estás el casco? A ver, yo cruzo muchos puentes, entonces tiene que "bancar" al estar pedaleando por la calle, ya hay la cosa de ser ciclista y por ser mujer siento de ah, usted no sabe andar en bicicleta, venga aquí que te voy a enseñar, tienes que estar en la ciclovía, no, estoy en la ciclovía y voy a transitar como cualquiera otro vehículo, es decir, tienes que estar armada y protegida, siempre muy tenso. Por otro lado, tiene días que hago enfoques constructivos como no le pregunté nada, porque dije eso? Usted está invadiendo un espacio por el cual no fue invitado y tengo reacciones que generan comentarios del tipo esas feministas, no te amo y tan poco eres gustosa, es desgastante, pero dentro del contexto a ser de construido y enfrentado.

Marina Harkot visualiza la autonomía como valor esencial en ser mujer ciclista urbana, incluso históricamente donde las mujeres tuvieron la posibilidad de salir de casa en una época que el papel femenino renegabas al cuidado de la familia generando ahora una individuación compartida por una visión de mundo y de temporalidad distintas:

La bicicleta tiene esa cosa de la autonomía marcada para la mujer porque es toda una organización del espacio urbano y la lógica de la ciudad de los muros y coches y, además, sumado a la construcción sociocultural de los papeles atribuidos a cada género desde la niñez, el poder de dar autonomía a cualquier persona y cuando se coloca a cualquier grupo que está en desventaja de acceso porque cuando se aumenta el acceso a una persona de baja renta, potencia aún más justamente por cargar un carácter revolucionario sumado a la cuestión de la desigualdad de género y en la dificultad de desplazarse en tener autonomía en la ciudad, está dando a la mujer la libertad de movilidad reducida por la propia lógica cultural del miedo, entonces explota, se da un empoderamiento y una manera de romper con la lógica, la mujer acaba llegando a donde, y la hora que ella quiere sin gastar, por ejemplo, voy a acompañarte en el punto de autobús, no, en bicicleta llegaré a donde quiera y nadie necesite a acompañarme porque lo hago todo sola, el miedo, la velocidad y la vulnerabilidad es otra, es una manera fantástica de autonomía y empoderamiento. 
Para Caroline Lemos, su implicación con el colectivo "Saia de Bici" convirtiéndose en una relación al percibir el pedalear como potencia emancipadora:

Comencé a notar que durante el camino que realizaba, tenía pocas mujeres pedaleando, creía extraño y me preguntaba: ¿por qué las mujeres no pedalean? Miedo de la calle o estereotipo de estar siempre ordenada con tacón alto y que no puede sudar. Empecé a hablar con las mujeres y se unió al colectivo Saia de Bici, que organiza paseos todo día 28 relacionado con el ciclo menstrual con salidas temáticas, a ejemplo, un día el tema fue playa y las mujeres fueron con ropa de playa para llamar la atención de la mujer pedaleando. Actualmente encuentro más compañeras pedaleando, es empoderamiento, cuando la bicicleta entró en el cotidiano de ellas, comenzaron a usar pantalones para pedalear en un momento que podrían salir solas pasando a reunirse y debatir cuestiones del ir-y-venir, es una liberación en la verdad, pero también tiene la cuestión absurda del acoso, oigo de amigas llevar tapa en el culo, puede caerse y se lastimar.

Ponderamos que las mujeres ciclistas urbanas resistentes están se refiriendo a una conciencia crítica de la realidad, pero por no teneres voz de mando, continúan sus vidas en medio de la locura del desplazamiento de las ciudades latinoamericanas y los gestores que prefieren olvidar que existen esas ciclistas urbanas al privilegiar a los motoristas que gozan detrás de su potente automóvil "sacando fina" de los ciclistas que no se entienden como semejantes al estar a la margen social. Ante esa totalidad hegemónica, quién excluye al otro del mundo de la calle?

\section{CONSIDERACIONES FINALES}

Partiendo del objetivo de la investigación en comprender los procesos educativos vivenciados por cicloactivistas en la promoción del ciclismo urbano, la categoría "La práctica del cicloactivismo" estructurada por las unidades de significado:

a) "Cicloturismo como praxis de liberación": el cicloturismo tornase una forma de cicloactivismo por caracterizarse como una práctica existencial libertadora, incluso reivindicadora de la condición marginalizada de ser ciclista urbano al conocer su entorno de forma transcendental más allá de la ciudad, también alternativa económicosocial, a ejemplo, la Vía Ecológica que promueve el pedalear en estradas rurales yendo al encuentro de la agricultura familiar como estrategia de sensibilización al proporcionar a las personas visualizar dónde viene los alimentos y como eso influencia la vida humana, también otra vivencia de la movilidad activa por bicicleta como forma de resistencia a la normalidad "casa-trabajo-consumo".

b) "Promoción del bicicultura": el caso del espacio de convivencia Bicicletaria Cultural, fortaleció la práxis cicloactivista en la comunicación de sus demandas, incluso con la organización del mayor evento temático en territorio latino-americano. Por otro lado, el proyecto Libera $T u$ Bici, además del servicio social generado con el agenciamento cultural hacen una crítica sobre la forma de vida organizada desde la cultura del automóvil similar al que el proyecto intenta rescatar en el ambiente de trabajo donde, además de los problemas de salud con el sedentarismo, el ciclismo urbano para trabajadores tornase una alternativa viable para mejorar la productividad laboral, la economía familiar y la construcción de comunidad.

c) "Ser mujer ciclista urbana" expone la condición del pedalear como derecho humano símbolo de la superación con el miedo del cuerpo frágil que la sociedad 
propaga en las mujeres portador de autonomía para superación de un contexto violento e intimidador de aquellos que miran la condición femenina solamente con carácter sexual, fruto de una comunicación masiva que molda el imaginario al visualizar esas relaciones de género como poco importantes para la comprensión humana, pero que actualmente, tiene promovido resistencia para su emancipación.

Creemos en la velocidad motorizado como una cualidad contemporánea violenta de la aceleración del tiempo en la constitución de no-lugares (AUGÉ, 2012). Esta condición genera relaciones poco civilizadas, a ejemplo, la practica cicloactivista evidencia la falta de control en la velocidad vial del transporte motorizado que causa riesgo a la vida humana y también de forma melindrosa, legitimase indiscriminadamente los estacionamientos de bienes privados en vías públicas por "voluntad pública" dificultando la implantación efectiva de infraestructura cicloviaria.

Por lo tanto, ese modo de vida está contextualizado en el interés políticoinstitucional melindroso para con el cuidado del reparto viario entre automóviles y movilidad activa, principalmente por el lobby de la industria automovilística que genera enormes recursos financieros inmediatos para todas las instancias del poder público, pero que no asumen las consecuencias de un desarrollo artificial dependiente estrictamente del fuentes no renovables de energía, lo que acaba por surgir innumerables dilemas éticos para una formación cultural donde el progreso debería contextualizarse como resultado de un proceso histórico-cognitivo-educativo de reflexión colectiva llevando en cuenta motricidades periféricas o marginales creadoras de ambientes con nuevas formas de habitar la ciudad basadas en la rebeldía y resistencia, no apenas un medio particular de movilizarse, sino modos de existencias ofrecidos por una cultura homogeneizadora.

Al presentarnos formas alternativas de habitar el mundo y de educar-se con bicicleta, expresamos el poema de Caroline Lemos recitado al final de su entrevista:

\footnotetext{
Si la placa dice pare, yo sigo a degustar cada milímetro porque puede ser que mañana me olvido de caer igual a la lluvia y escurrir como agua Yo, que ya desentendí el asfalto y atravesé el humo, deslizo en la ligereza inútil de las cosas. Porque puede ser que mañana me olvido de recorrer el camino inexplorado de la contramano, a encarar la subida más empinada. Por eso, yo rasgo los planes, rego las plantas y decoro los sueños porque puede ser que mañana me olvido de despertar.
} 


\section{REFERENCIAS}

ÁREA METROPOLITANA DEL VALLE DE ABURRÁ. Plan Maestro Metropolitano de la Bicicleta del Valle de Aburrá (PMB-2030). Medellín: Tranvías S.A.S. Transporte y vías, 2015. Disponible en: <http://www.encicla.gov.co/wp-content/uploads/5PMB2030.pdf>. Accedido en: 10 ene. 2019.

AUGÉ, M. Não-lugares: introdução a uma antropologia da supermodernidade. Campinas: Editora Papirus, 2012.

BELOTTO, J. C. A.; NAKAMORI, S.; NATARAJ, G.; PATRICIO, L. C. B. A cidade em equilíbrio: contribuições teóricas ao $3^{\circ}$ Fórum Mundial da Bicicleta. Curitiba: Proec/UFPR, 2014.

BICUDO, M. A. V. Pesquisa qualitativa segundo a visão fenomenológica. São Paulo: Editora Cortez, 2011.

BRASIL. Lei n. 13.724, de 4 de outubro de 2018: Programa Bicicleta Brasil (PBB). Brasília: Casa Civil, 2018. Disponible en: <http://www.planalto.gov.br/ccivil_03/_ato2015-2018/2018/Lei/L13724.htm>. Accedido en: 20 mar. 2019.

BRASIL. Caderno de Referência para Elaboração de Plano de Mobilidade Urbana. Brasília: Secretaria Nacional de Transporte e da Mobilidade Urbana, 2015. Disponible en: 〈http://www.cidades.gov.br/images/stories/ArquivosSE/planmob.pdf>. Accedido en: 13 ene. 2019.

BRASIL. Lei 12.587, de 3 de janeiro de 2012: Política Nacional de Mobilidade Urbana (PNMU). Brasília: Casa Civil, 2012a. Disponible en: <http://www.planalto.gov.br/ccivil_03/_Ato20112014/2012/Lei/L12587.htm>. Accedido en: 26 ene. 2019.

BRASIL. Resolução n. 466, de 12 de dezembro de 2012. Brasília: Ministério da Saúde/CNS, 2012 b. Disponible en: 〈http://conselho.saude.gov.br/resolucoes/2012/reso466.pdf〉. Accedido en: 10 dec. 2018.

BRASIL. Programa Bicicleta Brasil. Programa brasileiro de mobilidade por bicicleta. Caderno de referência para elaboração de Plano de Mobilidade por Bicicleta nas Cidades. Brasília: Secretaria Nacional de Transporte e da Mobilidade Urbana, 2007. Disponible en: <http://www.cidades.gov.br/images/stories/ArquivosSEMOB/Biblioteca/LivroBicicletaBrasil.pdf>. Accedido en: 25 ene. 2019.

BRASIL. Política Nacional de Promoção da Saúde (PNPS). Brasília: Ministério da Saúde, 2006. Disponible en: 〈http://bvsms.saude.gov.br/bvs/publicacoes/politica_nacional_promocao_saude_pnaps.pdf>. Accedido en: 28 ene. 2019.

BRASIL. Lei 10.257, de 10 de julho de 2001: Estatuto das Cidades. Brasília: Casa Civil, 2001. Disponible en: <http://www.planalto.gov.br/ccivil 03/leis/LEIS_2001/L10257.htm>. Accedido en: 29 ene. 2019.

BRASIL. Lei 9.503, de 23 de setembro de 1997: Código de Trânsito Brasileiro (CTB). Brasília: Casa Civil, 1997. Disponible en: 〈http://www.planalto.gov.br/Ccivil 03/leis/L9503.htm>. Accedido en: 28 ene. 2019.

CARDOSO, J. H.; KARAM, L. M.; SANTOS, J. S. Cicloturismo e agroecologia: vetores para a sustentabilidade territorial. Pelotas: Embrapa Clima Temperado - Boletim de Pesquisa e Desenvolvimento, 2016. Disponible en: 〈https://www.infoteca.cnptia.embrapa.br/infoteca/bitstream/doc/1075184/1/Boletim244.pdf>. Accedido en: 12 ene. 2019.

CARMO, C. S. Epistemologia da bicicleta: processos educativos emergentes na prática do pedalar. 2017. 453 p. Centro de Educação e Ciências Humanas, Universidade Federal de São Carlos, São Carlos, 2017. 
COLVILLE-ANDERSEN, M. Copenhagenize: the definitive guide to global bicycle urbanism. Washington: Island Press, 2018.

DENZIN, N. K.; LINCOLN, Y. Manual de investigación cualitativa. Barcelona: Editorial Gedisa, 2012.

DURT, C.; FUCHS, T.; TEWES, C. Embodiment, enaction, and culture. Investigating the constitution of the shared world. Masachussetts: MIT Press, 2017.

ECF. Cycling delivers on the global goals. Shifting towards a better economy, society and planet for all. Bruxelles: Europe Cyclists Federation (ECF) and World Cycling Aliance, 2016. Disponible en: <https://ecf.com/sites/ecf.com/files/The\%20Global\%20Goals internet.pdf〉. Accedido en: 20 nov. 2019.

GEHL, J. Cidades para pessoas. 3. ed. São Paulo: Perspectiva, 2013.

GONÇALVES JUNIOR, L.; CORRÊA, D. A.; CARMO, C. S.; TORO-ARÉVALO, S. A. Diarios de bicicleta: procesos educativos vivenciados en la Ruta de las Emociones. Estudios Pedagógicos, v. 42, n. 1, p. 323-337, 2016.

HARKOT, M. K. A bicicleta e as mulheres: mobilidade ativa, gênero e desigualdades socioterritoriais em São Paulo. 2018. 192 p. Dissertação (Mestrado em Planejamento Urbano e Regional) - Faculdade de Arquitetura e Urbanismo, Universidade de São Paulo, São Paulo, 2018.

ILLICH, I. Energía y equidad. Los límites sociales de la velocidad [1974]. Madrid: Díaz \& Pons, 2015.

JONAS, H. O princípio responsabilidade. Ensaio de uma ética para a civilização tecnológica. Rio de Janeiro: Contraponto Ed. PUC-Rio, 2006.

KIVERSTEIN, J. Extended Cognition. In: NEWEN, A.; DE BRUÍN, L.; GALLAGHER, S. The Oxford Handbook of 4E Cognition. Oxford: Oxford University Express, 2018. p. 19-38.

MANFIOLETE, L. D.; BERSI, R. M. Pedaling for Cityzenship. Rio Claro, 2016. Disponible en: $\langle$ https://www.youtube.com/watch?v=3sudXITFGcE\&t=53s $>$. Accedido en: 13 ago. 2018.

NATARAJ, G. O grande meio dia. Curitiba: L-Dopa Publicações, 2013.

NEWEN, A.; DE BRUÍN, L.; GALlAGHER, S. 4E Cognition: Historical Roots, Key Concepts and Central Issues. In: NEWEN, A.; DE BRUÍN, L.; GALLAGHER, S. The Oxford Handbook of $\mathbf{4 E}$ Cognition. Oxford: Oxford University Express, 2018. p. 3-15.

OLIVEIRA, M. W.; SILVA, P. B. G.; GONÇALVES JUNIOR, L.; MONTRONE, A. V. G.; JOLY, I. Z. L. Processos educativos em práticas sociais: reflexões teóricas e metodológicas sobre pesquisa educacional em espaços sociais. In: OLIVEIRA, M. W.; SOUZA, F. R. (Orgs.). Processos educativos em práticas sociais: pesquisas em educação. São Carlos: Editora UFSCar, 2014. p. 29-46.

ONU. Mobilizing Sustainable Transport for Development. Analysis and Policy Recommendations from the United Nations Secretary-General's High-Level Advisory Group on Sustainable Transport. New York: United Nations Ban Ki-moon, 2016a. Disponible en: $<$ https://sustainabledevelopment.un.org/content/documents/2375Mobilizing\%20Sustainable\%20Transport .pdf>. Accedido en: 13 oct. 2018.

ONU. Urbanization and Development: Emerging Futures. Nairobi: United Nations (UN) World Cities Report Human Settlements Programme, 2016b. Disponible en: $<$ http://wcr.unhabitat.org/?wcr_process_download=1\&download_id=117118>. Accedido en: 22 nov. 2018.

ONU. Transforming our world: the 2030 agenda for sustainable development Sustainable development. Ginebra: United Nations Sustainable Development Goals (SDG), 2015a. Disponible en: $<$ http://www.un.org/sustainabledevelopment/sustainable-development-goals/>. Accedido en: 17 nov. 2018. 
ONU. Convención Marco sobre el Cambio Climático (FCCC). Paris: Naciones Unidas (COP-21), 2015b. Disponible en: 〈https://unfccc.int/resource/docs/2015/cop21/spa/01s.pdf>. Accedido en: 13 sep. 2018.

PATRICIO, L. C. B. Mobilidade corporativa: análise das medidas de incentive ao uso da bicicleta como transporte ao trabalho em Curitiba-PR. 2016. 138 p. Dissertação (Mestrado em Gestão Urbana) - Escola de Arquitetura e Urbanismo, Pontifícia Universidade Católica do Paraná, Curitiba, 2016.

PUCHER, J.; BUEHLER, R. City Cycling. Cambridge: MIT Press, 2012.

RIECHMANN, J. El socialismo puede llegar sólo en bicicleta. Ensayos ecosocialistas. Madrid: Los Libros de la Catarata, 2012.

SALDIVA, P. Vida urbana e saúde: os desafios dos habitantes das metrópoles. São Paulo: Contexto, 2018.

SARMIENTO, O. L.; CASTILLO, A. D.; TRIANA, C. A.; ACEVEDO, M. J.; GONZALEZ, S. A.; PRATT, M. Reclaiming the streets for people: Insights from Ciclovías Recreativas in Latin America. Preventive Medicine, v. 103, Suppl., S34-S40, 2017.

SERGIO, M.; TRIGO, E.; GENÚ, M.; TORO, S. Motricidad humana. Una mirada retrospectiva. 2. Ed. ver. ampl. Alcalá de Henares: Léeme - Instituto Internacional del Saber, 2014.

SERRES, M. Variaciones sobre el cuerpo. Ciudad de Mexico: Fondo de la Cultura Económica, 2011.

TORO-ARÉVALO, S. A. Motricidad, en-acción y fenomenología: la articulación conceptual de la existencia. Motricidades: Rev. SPQMH, v. 1, n. 1, p. 78-90, 2017.

TORO-ARÉVALO, S. A.; MAUTZ, P. V. Educación para y desde la militancia y la transformación social: nuevas relacionalidades didácticas. In: DOÑA, Alberto M.; HERRERA, Marcelo A. (Orgs.). Educación y Transformación social. Construyendo una ciudadanía crítica. Valparaiso: Ediciones Pontificia Universidad de Valparaiso, 2014. p. 47-55.

Recibido en: 02 feb. 2019.

Aprobado en: 17 abr. 2019. 